\title{
Novel sustainable metallic powder production process with water used as milling medium
}

\author{
Melchor Salazar ${ }^{1} \cdot$ Héctor Carreón ${ }^{2} \cdot$ Flavio Américo Lagos ${ }^{3}$ \\ Received: 12 June 2021 / Accepted: 5 October 2021 / Published online: 23 October 2021 \\ (c) The Author(s), under exclusive licence to Springer-Verlag GmbH Germany, part of Springer Nature 2021
}

\begin{abstract}
Today, $\mathrm{Fe}-\mathrm{Al}$ intermetallic compounds are receiving a great interest from the mechanical, aerospace, and biomedical industries. A novel production process for $\mathrm{Fe}-\mathrm{Al}$ intermetallic powders based on the generation of metallic tapes by rapid solidification and disintegration by water vapor was proposed. In this research work, a comparison is made between the energy required to manufacture of $\mathrm{Fe}-\mathrm{Al}$ powder using the aforementioned process and one of the most commonly used manufacturing processes within the industry such as mechanical alloying. In addition, some other benefits of the proposed manufacturing process are analyzed. To carry out this comparison, the theoretical equations that take into account the most important variables involved during the process such as the type of material and hardness, the initial and final particle size, the grinding stages and the heating of the treatment powder were considered. In the case of calculating the energy required for the new proposed process, the two main stages were considered such as (1) the production of FeAl metal tape and (2) the subsequent transformation of the tape into powder by means of injection water vapor. For the first stage, the CASTRIP process is considered, and for the second stage, the energy required for the generation steam. Although the calculations may have certain limitations, it is obvious that the energy required to $\mathrm{Fe}-\mathrm{Al}$ powder production using the new process is much lower than that required by mechanical alloying, resulting in at least three orders of magnitude lower $\left(2.75 \times 10^{6}\right.$ versus $2.206 \times 10^{9} \mathrm{~kJ} / \mathrm{ton}$ ). This lower energy implies considerable economic savings in the production process. On the other hand, when using water as a grinding medium during the process, it results in less environmental and acoustic pollution, less manipulation risks for humans and finally, no harmful agents or additives are used, making the proposed process sustainable.
\end{abstract}

Melchor Salazar

msalazarm@ipn.mx

1 Centro de Innovación e Integración de Tecnologías Avanzadas, Unidad Papantla Veracruz del Instituto Politécnico Nacional, Innovation Coordination, C.P. 93400, Papantla de Olarte, Veracruz, Mexico

2 Instituto de Investigaciones Metalúrgicas (UMSNH), Ciudad Universitaria, 58000-888 Morelia, Mexico

3 Instituto Mexicano del Petróleo, Product Technology Direction, Eje Central Lázaro Cárdenas 152,

C.P. 07730 Mexico City, Mexico 


\section{Graphic abstract}

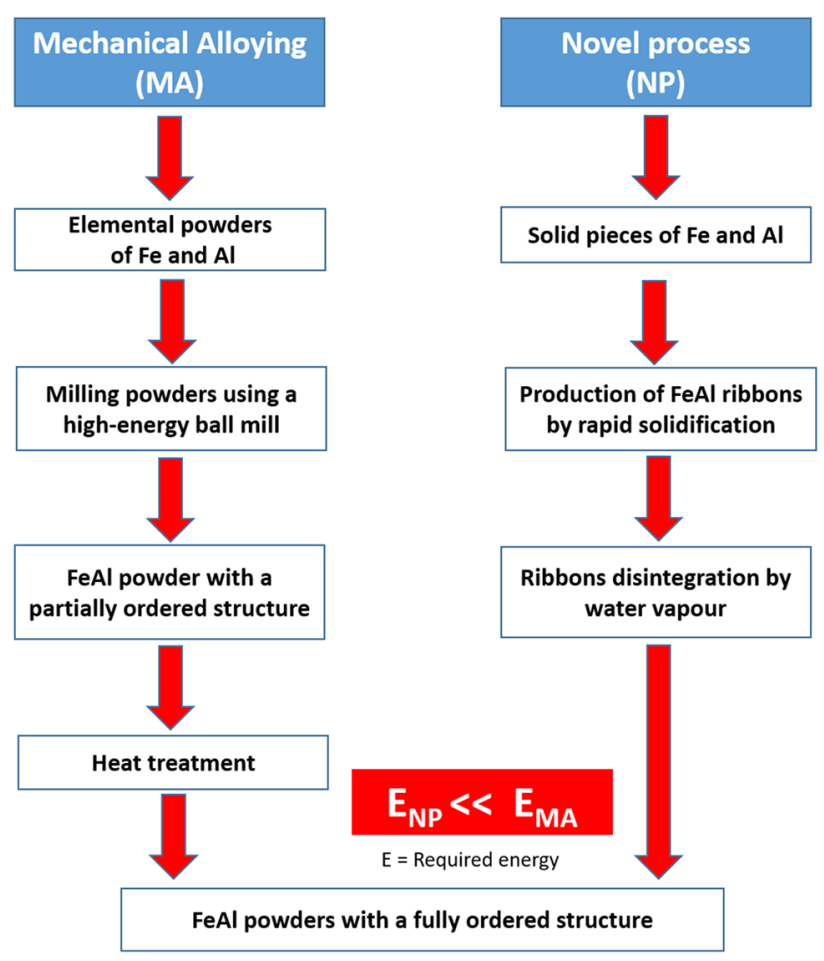

Keywords Sustainable process $\cdot$ Iron aluminide $\cdot$ Powder $\cdot$ Mechanical alloying

\section{Introduction}

Iron aluminide intermetallics were developed as structural and coating material due to their excellent high-temperature oxidation and corrosion resistance in aggressive environments, low density, high strength/weight ratios, and low cost (Zamanzade et al. 2016). Due to such properties, these intermetallic compounds have a great potential for substituting stainless steel in some industrial applications at elevated temperatures (Paidar 2015) and also have advantages over nickel and titanium aluminides (Feijó Leão Borges et al. 2014). The application of this type of materials is mainly in the filtration and coal gasification systems in the oil industry, fuel injection nozzles, brake disks for windmills and trucks, automobile exhaust systems (Zamanzade et al. 2016; Michalcová et al. 2020), among others. However, they are industrially limited due to their low ductility at room temperature (Chen and Liu 2001).

Several researchers have reported interesting results at the iron aluminide intermetallics in order to improve the low ductility at room temperature by appropriate processing and by the addition of alloying elements (Hamlati et al. 2020; Morris and Muñoz-Morris 2011), through melting and conventional casting (Alexander et al. 1998; Feijó Leão Borges et al. 2014), grain refinement (Hu et al. 2003) and powder metallurgy (PM) methods (Godlewska et al. 2003; Meyer et al. 1999). However, these intermetallics have presented higher tensile elongations and fracture energy on impact testing due to the finest microstructures (Pithawalla et al. 2002; Sleboda and Doniec 2007).

Some of the common fabrication processes of the $\mathrm{Fe}-\mathrm{Al}$ powder are MA (Chebli et al. 2020; Michalcová et al. 2020), chemical synthesis, additive manufacturing as laser-based processes (Peska et al. 2020) combustion reaction and flowlevitation methods. MA is the most common process used for producing $\mathrm{Fe}-\mathrm{Al}$ intermetallic compounds. Metal powders also result in a good alternative to improve performance and sustainability for metal additive manufacturing. This process has been used for a long time in injection molding processes and as coatings. Actually, metal powders are very successful for filling or volume forming processes due to powder particles packing. This phenomenon affects the final product density (Digital Alloys' Guide to Metal Additive Manufacturing-Part 7 2019).

Human life has a very great influence on earth's environment through waste streams generated by different processes of mankind activities; for example, the iron from ferrous sludge from water clarification immobilizes the phosphorous 
if it gets into the soil (Marousek et al. 2019). Industrial activities have a prime role for the kind of different types of streams outgoing its production processes, which influence the surroundings with heat, noise, chemical substances with polluting potential for water, air and soil. Our planet has given us signs of recovery in the past months, during lockdown due to Covid-19, when human activities were diminished to a very substantial point. It is therefore extremely important to establish sustainable process in all orders of our life to reduce human pollution in all type of activities. Metallurgical activities are very important to our lives through the type of products delivered. It is also considerable the extent of energy it consumes in productive processes.

Industry has always been looking for ways to reduce the energy consumed in manufacturing processes and implement smart manufacturing based solutions to make its processes more efficient through cyber-physical systems or manufacturing systems of Industry 4.0 (Throne and Lăzăroiu 2020; Androine et al. 2021) with learning techniques (Valaskova et al. 2020; Kliestik et al. 2020) or reduce the machining to obtain the final product (Campatelli et al. 2015) to improve the value chain of the production sector. However, at present, due to the environmental conditions in which our planet encounters, it is also important to develop more environmentally friendly (Paul et al. 2014) and sustainable manufacturing processes (Dornfeld 2014).

In this paper is proposed a novel powder producing process for $\mathrm{FeAl}$ intermetallic compounds, using water vapor as a milling medium to produce powders, instead of high-energy-demanding process called MA in ball mills, with low efficiency and very considerable noise and vibration production. The new process applies rapid solidification to produce ribbons which are then exposed to water vapor and the powder is generated in this way. This process described in detail in a former paper (Salazar et al,

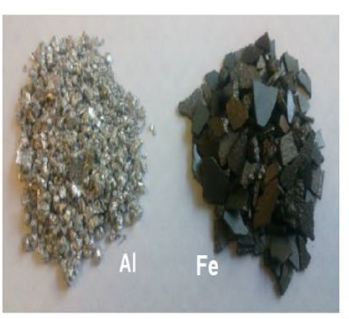

Raw material

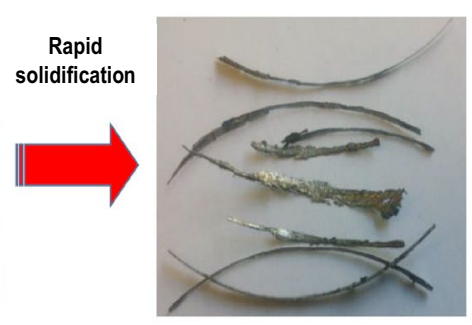

FeAl ribbons
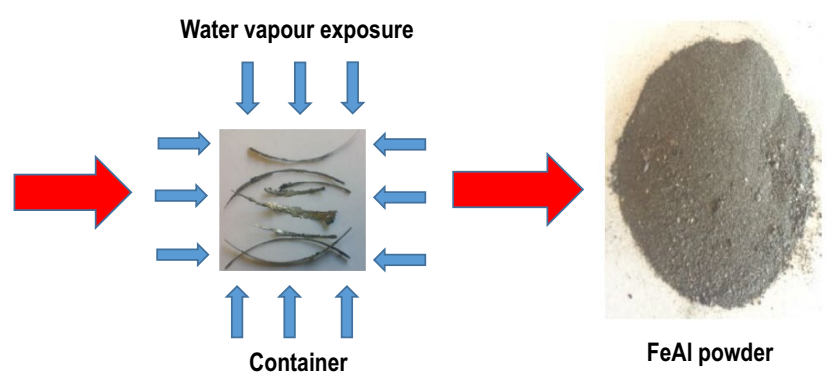

Fig. 1 Novel fabrication process of FeAl powder developed by the authors (Salazar et al. 2016). FeAl ribbons + water vapor $=\mathrm{FeAl}$ powder. When using rapid solidification and water vapor, less energy will
2016) requires theoretically less energy than the MA, nonpolluting and less hazardous in operation and production. The objective of this paper is to evaluate this hypothesis by means of computations performed to estimate the energy required to produce $\mathrm{FeAl}$ powders by $\mathrm{MA}$ as well as by energy savings and other benefits.

Different numerical methods have been developed to estimate several properties and behavior of dispersions and nanofluids (dispersions of nanometric particles), such as dynamic viscosity (Goodarzi et al. 2019; Khodadadi et al. 2019), thermal conductivity (Shahsavar et al. 2019; Soltani et al. 2020), flow and heat transfer (Moradi et al. 2019) and rheological behavior (Hussein et al. 2018; Yan et al. 2020). However, for this research theoretical equations (Tsakalakis and Stamboltzis 2004; Mhadhbi et al. 2013) and industrial data (Campbell 2004; Ibarrondo 2008), which consider the different variables involved in the two production processes, were evaluated.

\section{Materials and methods}

\section{Fabrication of FeAl powders using novel process}

The proposed fabrication process consists essentially of two main stages (Salazar et al. 2016) as observed in Fig. 1:

FeAl ribbons production by rapid solidification (melt spinning) from solid aluminum and iron pieces, not from elemental powders as used by MA.

$\mathrm{FeAl}$ ribbons produced are exposed to steam in a container for their disintegration and transformation into powder. The particle size and its distribution can be controlled by the addition of alloying elements. the new process and then to compare them to demonstrate

be required for powder production compared to MA, and it becomes more environmentally friendly 


\section{Using MA process}

MA is a powder processing technique that involves the repeated welding, fracturing, and re-welding of a mixture of powder particles. MA process is a common process which involves a high-energy ball mill producing alloys and microstructures that are not possible to produce by standard metallurgical practices such as casting and forging. MA process also uses aluminum and iron powders as raw materials. This procedure is carried out in different types of high-energy equipment, such as vibratory and planetary mills, high-speed blenders and shakers (e.g., high-energy Spex), and largediameter ball mills (Mhadhbi et al. 2013).

\section{Results and discussion}

\section{Required energy comparison for producing FeAl powders by MA and new process}

In this section, a comparison between the required energy for $\mathrm{MA}$ and the novel process for producing FeAl powder was performed considering each stage of the processes which is schematically represented in Fig. 2. This figure shows a representation of the steps for each involved process for computing the energy involved for each case. First, the required energy for a conventional MA process using a high-energy ball mill was computed. The second part corresponds to the estimation of the required energy for our new process, with both steps (Rapid solidification and disintegration), already described in Section 2.1 .

For the calculation of the energy required in the MA process, it is important to take into account that the powders obtained have a partially ordered structure and therefore a later heat treatment is necessary to get a fully ordered structure (Hu et al. 2003; Tecnum, University of Navarra, Spain), as shown in Fig. 2.

\section{Required energy for MA}

In this section, the use of a high-energy ball mill is considered because it is one of the most commonly used processes for producing $\mathrm{FeAl}$ powders. The theoretical energy required for producing $\mathrm{FeAl}$ powder $\left(E_{\mathrm{Ball}}\right)$ was calculated considering the energies required in the two process steps: (1) the milling itself $\left(E_{\text {Mill }}\right)$ with two stages and (2) the heat treatment $\left(E_{\mathrm{Ht}}\right)$ applied later to the produced powder. Minimum theoretical energy required for the full process can be expressed in the following way:

$E_{\text {Ball }}=E_{\mathrm{Mill}}+E_{\mathrm{Ht}}$

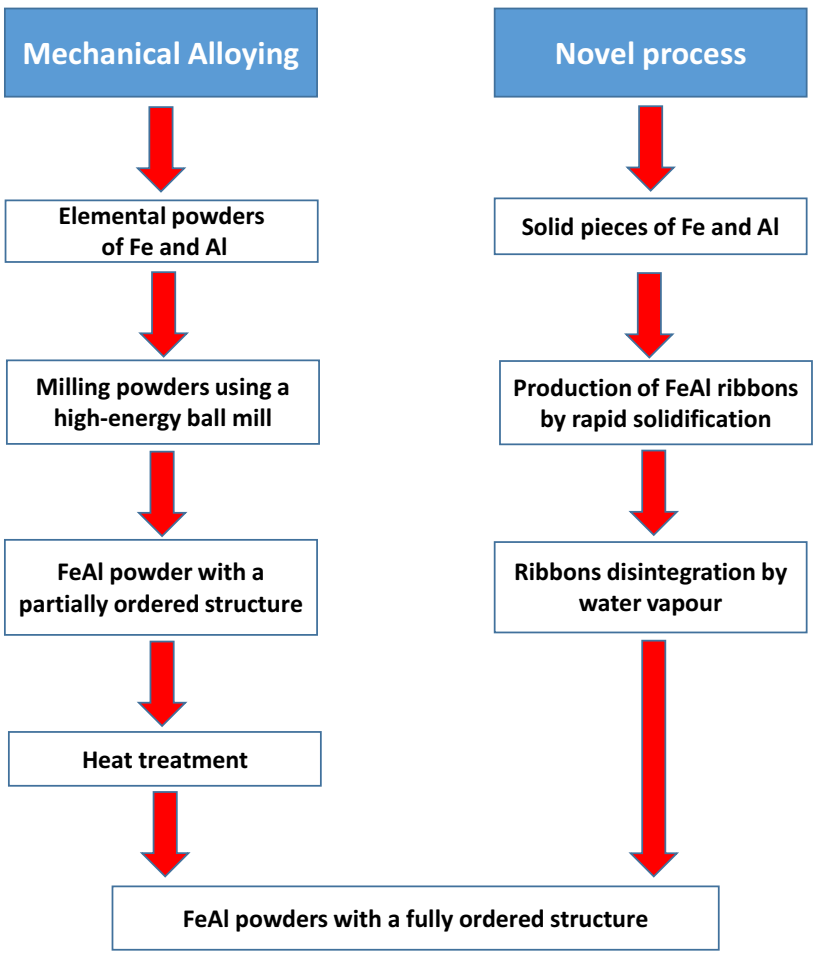

Fig. 2 Both processes involved for the theoretical energy computations: MA and novel process. To calculate the required energy, it is important to identify the stages involved in each process. Important differences can be observed: raw material, equipment used and number of stages

where $E_{\mathrm{Ball}}=$ required energy for producing $\mathrm{FeAl}$ in a ball mill, $E_{\mathrm{Mill}}=$ required energy for milling, and $E_{\mathrm{Ht}}=$ required energy for heat treatment.

For the calculation of the required energy, the following considerations are made: the intermetallic compound has a high hardness, the mean size for the feed particle diameter $D_{\mathrm{f}}=10 \mathrm{~mm}$, and final product particle diameter $d=40 \mu \mathrm{m}$ (mean size of the powder particles produced). The milling energy was computed according to Tsakalakis and Stamboltzis (2004). The milling process is considered to be undertaken in two stages:

$E_{\text {Mill }}=E_{b 1}+E_{b 2}$

where $E_{b 1}=$ Required energy for the first milling step in ball mill, $E_{b 2}=$ required energy for the second milling step in ball mill.

For the first milling stage, the specific grinding energy $W_{\mathrm{h}}$ is computed according to the material hardness. In this case, since iron aluminide is considered a hard compound, $W_{\mathrm{h}}$ can be expressed as:

$W_{\mathrm{h}}=1961\left(D_{\mathrm{f}}^{0.193}\right) \times d^{-0.962}$

Substituting the values of $D_{\mathrm{f}}$ and $d$, we have 
$W_{h}=67.6544 \frac{\mathrm{kW}}{\mathrm{sh} \text { ton }}$

The power draw $P$ for the ball mill is given by

$P=0.1169 W_{\mathrm{h}} D_{\mathrm{f}}^{0.193} d^{-0.962} T$

where $T$ is the required mill production capacity in short ton/h (in this case, 1 ), resulting in

$P=272.853 \mathrm{kWh} / \mathrm{ton}$

This power draw result is correlated with the common value given for the computation of the required energy for ball mills, according to the Denver slide rule (Tsakalakis and Stamboltzis 2004), resulting from a correlation for industrial ball mills, and considering different methods, given by the model of these authors, the calculated power draw $(E)$ results in $E=340 \mathrm{kWh} /$ ton and this gives for the first milling step (with $34 \%$ increase for this step). Converting this value to $\mathrm{kJ} / \mathrm{ton}$, we have:

$E_{b 1}=1.224 \times 10^{6} \mathrm{~kJ} / \mathrm{ton}$

The second milling stage requires about $33 \%$ more energy than this one (Mhadhbi et al. 2013), resulting in:

$E_{b 2}=1.628 \times 10^{6} \mathrm{~kJ} / \mathrm{ton}$

and the total milling energy (from Eq. 2) results in:

$E_{\text {Mill }}=2.852 \times 10^{6} \mathrm{~kJ} / \mathrm{ton}$

As mentioned above, a heat treatment is required for powders produced by MA. Considering that the heat treatment for this intermetallic compound is carried out at $650{ }^{\circ} \mathrm{C}$ (Mhadhbi et al. 2013), the energy involved for the process to reach that temperature $\left(E_{\mathrm{Ht}}\right)$ is computed as follows:

$E_{\mathrm{Ht}}=C p \Delta T m$

where $E_{\mathrm{Ht}}=$ energy for heat treatment, $C p=$ heat capacity $=0.51 \mathrm{~kJ} / \mathrm{kg}{ }^{\circ} \mathrm{K}$ (according to Piatkowski et al. 2013), $\Delta T=$ temperature difference (between heat treatment and MA), $m=$ mass considered, for this case, 1 ton.

Thus

$E_{H t}=0.457 \times 10^{6} \mathrm{~kJ} / \mathrm{ton}$

With this result, the minimum theoretical energy required for the full process according to Eq. (1) is:

$E_{\text {Ball }}=3.309 \times 10^{6} \mathrm{~kJ} / \mathrm{ton}$

Considering the energy consumed by the particle surface relative to the original particle surface energy, the efficiency for this type of process is very low, 5\% (Mhadhbi et al. 2013). Therefore the total theoretical required energy for a ball mill ( $\left.E_{\text {Ball total }}\right)$ is:

$$
E_{\text {Ball total }}=\frac{3.309}{0.05} \times 10^{6} \mathrm{~kJ} / \mathrm{ton}=6.618 \times 10^{7} \mathrm{~kJ} / \mathrm{ton}
$$

Most energy losses for this process are mainly in the form of noise and heat. For hard powders, milling efficiency is very low, about $3 \%$ because their particles adhere to each other and the ball impacts become inelastic. This efficiency gives the real energy to be supplied for process in ball mill $\left(E_{\text {Ball real }}\right)$ to be supplied:

$E_{\text {Ball real }}=\frac{6.618}{0.03} \times 10^{7} \mathrm{~kJ} / \mathrm{ton}=2.206 \times 10^{9} \mathrm{~kJ} / \mathrm{ton}$

\section{Required energy for the novel process}

As it is mentioned above, the new process consists of two main steps: the intermetallic ribbons production by rapid solidification and their subsequent disintegration with steam. Therefore, the energy required for this novel process $\left(E_{\mathrm{NP}}\right)$ can be expressed for the following equation:

$E_{\mathrm{NP}}=E_{\mathrm{rib}}+E_{\mathrm{dis}}$

where $E_{\mathrm{NP}}=$ energy required for the new process, $E_{\text {rib }}=$ energy required for ribbons production, and $E_{\mathrm{dis}}=$ energy required for ribbons disintegration.

For the first step, the production of ribbons, the required energy $\left(E_{\mathrm{rib}}\right)$ will take as reference value the industrial process CASTRIP (Campbell 2004; Ibarrondo 2008) for melt spinning energy. This was made because of the scarcity of data for scaling-up our process from laboratory scale to industrial practice. The reported value is $0.18 \mathrm{GJ} /$ ton $=1.8 \times 10^{5} \mathrm{~kJ} /$ ton. It is important to take into account that this value is given for steel casting process in thin slabs and in our case the required energy is lower, according to composition, with 60 at.\% aluminum and the balance of iron.

$E_{\text {rib }}=1.8 \times 10^{5} \mathrm{~kJ} / \mathrm{ton}$

The energy for the second step (disintegration using steam, $\left.E_{\mathrm{dis}}\right)$ is given by the energy for heating water to the boiling point $\left(E_{\mathrm{dis} 1}\right)$ and the corresponding latent heat for vapor production $\left(E_{\mathrm{dis} 2}\right)$ :

$E_{\mathrm{dis}}=E_{\mathrm{dis} 1}+E_{\mathrm{dis} 2}$

where

$E_{\text {dis } 1}=C p \Delta T m$

$C p=$ heat capacity $=4.1813 \mathrm{~kJ} / \mathrm{kg}{ }^{\circ} \mathrm{K}, \Delta T=$ temperature differential $\left(100-25^{\circ} \mathrm{K}\right), m=$ mass considered, for this case, 1 ton. 
Substituting

$E_{\mathrm{dis} 1}=3.13 \times 10^{5} \mathrm{~kJ} / \mathrm{ton}$

and

$E_{\text {dis } 2}=m Q_{\text {lat }}$

where $m=$ mass considered, for this case, 1 ton, $Q_{\text {lat }}=$ latent heat of water $=2257 \times 10^{3} \mathrm{~kJ} / \mathrm{kg}$.

Substituting

$E_{\mathrm{dis} 2}=2.257 \times 10^{6} \mathrm{~kJ} / \mathrm{ton}$

The total energy required for the disintegration step results in:

$E_{\text {dis }}=(0.313+2.257) \times\left(10^{6} \mathrm{~kJ} /\right.$ ton $)=2.570 \times 10^{6} \mathrm{~kJ} /$ ton

Total energy required for the process according to Eq. 6 is:

$$
E_{\mathrm{NP}}=(0.18+2.570) \times 10^{6} \mathrm{~kJ} / \text { ton }=2.75 \times 10^{6} \mathrm{~kJ} / \mathrm{ton}
$$

An average value for this type of milling process obtained from the literature is in the range $2.0 \times 10^{12}$ to $9.757 \times 10^{12} \mathrm{~kJ} /$ ton, according to industrial data (EPRI Center of Materials Production 2000). The obtained value by us for ball mill MA process, $\left(W_{\text {Ball real }}\right)=2.206 \times 10^{9} \mathrm{~kJ} /$ ton, is lower than that reported for the industrial practice, as can be seen above. The employed model considers particle sizes and hardness referred to a large number of analyzed systems for the ball mill. Although there are limitations in our theoretical computations, because of the assumptions made, it can be clearly observed that the required energy for powder by MA is much higher than that required by the new process. As future work, numerical simulation techniques (Lenhard et al. 2019) can be employed to get results that adjust more accurately those of industrial practice. However, for the purpose of this paper, it results enough to show energy savings using the new process considering the main variables affecting both processes.

The proposed new process offers important energy savings, considering that a more efficient process (rapid solidification) and then water vapor are employed. The results obtained here show an important difference between the theoretical energies used for the ball mill and that used for the new process (at least 3 orders of magnitude).

The required energy results shown here are the first part of the assessment for this new proposed process. More studies and analysis are required to determine the implementation of this process to industrial scale (Marousek et al. 2015), such as process sustainability (Marousek et al. 2020), generation of hazardous residues (Mardoyan and Braun 2015), detailed financial assessment, the use of bankruptcy prediction tools to ensure business continuity and further sustainability and ethically responsible economic development (Kliestik et al. 2018), among other important issues.

\section{Other benefits from the new process}

Most of the processes used to produce iron aluminide powders utilize elemental powders of iron and aluminum as raw materials. Therefore, some other advantages of the new process refer to the absence of particle emissions to the environment and the corresponding health and security hazards originated by suspended particles with high pyrogenic character caused by excessive impact energy transfer. This condition involves important security measures to be adopted, including handling the material under inert gas atmosphere, such as argon. The new process prevents health risks resulting from powders or hazardous conditions, which can result from the contact of the mentioned produced powders with the skin or when inhaled. No lubricants or binders, such as stearates, as is the case in MA (Soni 2001; Khaerudini et al. 2013), are used. The corresponding pollution and environmental hazards by these agents are also reduced.

The metal powders produced by milling (MA) are hardened, irregular in shape and have low fluidity and filling density. In the case of the novel process, there is no contamination with the material from the milling vessel nor from ball debris.

Water vapor decomposes in hydrogen and oxygen by interaction with reactive aluminum from the intermetallic compound. Oxygen forms alumina, and hydrogen is released from the reaction and diffuses into the material. There is no generation of contaminated water (Salazar et al. 2016).

Fixed or investment costs (CAPEX) considered for ball mill are also saved through this process, as well as the corresponding operating costs (OPEX) for the milling process. Environmental and health risks are remarkably reduced too. The ease to handle the material as ribbons or powder without any further security measure, such as inert gas atmosphere or special protection equipment for the personnel, represents also important savings in operation costs.

The reaction between water vapor and aluminum also generates hydrogen (Salazar et al. 2016, 2005). Others authors have proposed hydrogen production using iron aluminides (López-Miranda and Rosas 2019; Romero-Romero et al. 2014; García de León et al. 2013). This suggests that this method could be used to produce hydrogen; however, it requires more studies. These advantages are very important in this industrial branch, which is very intensive energy demanding one.

\section{Conclusions}

In this research work, a novel method is proposed for producing powder of FeAl intermetallic compounds, which can be used to produce any type of powder with high aluminum 
content and other aluminides such as titanium and nickel aluminides among others. The process consists mainly of two stages: metallic ribbons production and their disintegration by exposure to water vapor. Process details have been described in a former article by the authors (Salazar et al. 2016). In this paper, some benefits of this new process are shown: required energy for FeAl powder production using: (a) the new process developed by the authors and (b) one of the more commonly used processes, mechanical alloying (MA).

Required energy for intermetallic FeAl manufacturing by the new proposed process is considerable lower (at least 3 orders of magnitude) than that required by MA, $2.75 \times 10^{6} \mathrm{~kJ} /$ ton for the new process vs. $2.206 \times 10^{9} \mathrm{~kJ} /$ ton for MA. Although the computed value for MA could be higher according to reported data from industrial practice (in the range of $2.0 \times 10^{12}$ to $9.757 \times 10^{12} \mathrm{~kJ} /$ ton), it results in obviously the lower energy required to produce FeAl by the new proposed process. According to these results, the new process consumes less energy to produce FeAl powder. As mentioned before, it employs rapid solidification and water vapor, instead of high-energy equipment, such as ball mill.

Besides energy and capital savings, environmental, health and work risks are remarkably reduced too due to the use of water vapor.

This manufacturing process represents a good example of a sustainable and environmentally friendly one. This process is a good example of the new trend to use less energy in industry.

More studies and analysis are required to determine the implementation of this process to industrial scale.

\section{References}

Alexander DJ, Maziasz PJ, Wright JL (1998) Processing and alloying effects on tensile and impact properties of $\mathrm{FeAl}$ alloys. Mater Sci Eng A A258:276-284. https://doi.org/10.1016/S0921-5093(98) 00945-9

Andronie M, Lăzăroiu G, Stefanescu R, Uta C, Dijmarescu I (2021) Sustainable, smart, and sensing technologies for Cyber-Physical manufacturing systems: a systematic literature review. Sustainability 13:5495. https://doi.org/10.3390/su13105495

Campatelli G, Scippa A, Lorenzini L, Sato R (2015) Optimal workpiece orientation to reduce the energy consumption of a milling process. Int J Precis Eng Manuf Green Technol 2(1):5-13. https:// doi.org/10.1007/s40684-015-0001-3

Campbell PC (2004) The CASTRIP process: a revolutionary casting technology, an exciting opportunity for unique steel products or a new model for steel micro-mill?

Chebli A, Djekoun A, Sunol JJ, Ninansky D (2020) Structural, magnetic and thermal characterization of Fe 50 Se 50 powders obtained by mechanical alloying. doi: https://doi.org/10.1007/ s10973-019-08772-x. http://hdl.handle.net/10256/18847

Chen GL, Liu CT (2001) Moisture induced environmental embrittlement of intermetallics. Int Mater Rev 46:253-270. https://doi.org/ $10.1179 / 095066001771048718$
Dornfeld DA (2014) Moving towards green and sustainable manufacturing. Int J Precis Eng Manuf Green Technol 1(1):63-66. https:// doi.org/10.1007/s40684-014-0010-7

Energy Consumption in metal additive manufacturing, 2019. https:// www.digitalalloys.com/blog/energy-consumption-metal-additivemanufacturing/

EPRI Center of Materials Production, Metal powder production, industry segment profile, SIC 33991, Columbus, OH, U.S.A (2000)

Feijó Leão Borges D, Crocce Romano Espinosa D, Geraldo Schön C (2014) Making iron aluminides out of scrap. J Mater Res Technol 3(2):101-106. https://doi.org/10.1016/j.jmrt.2013.12.002

García de León Monter E, Tellez O, Patiño-Carachure C, Angeles Chávez C, Rosas R (2013) Evaluation of hydrogen embrittlement in FeAl assisted by mechanical milling. Acta Microsc 22(3):262-268

Godlewska E, Szczepanik S, Mania R, Krawiarz J, Koziñski S (2003) $\mathrm{FeAl}$ materials from intermetallic powders. Intermeallics 11:307312. https://doi.org/10.1016/S0966-9795(02)00247-9

Goodarzi M, Toghraie D, Reiszadeh M, Afrand M (2019) Experimental evaluation of dynamic viscosity of ZnO-MWCNTs/engine oil hybrid nanolubricant based on changes in temperature and concentration. J Therm Anal Calorim 136:513-525. https://doi.org/ 10.1007/s10973-018-7707-8

Hamlati Z, Otmane F, Mechri H, Laslouni W, Azzaz M (2020) Effects of minor elements additions to the nanocrystalline $\mathrm{FeAl}$ alloy produced by powder metallurgy. Mater Sci Forum 1005:3-9.

$\mathrm{Hu}$ W, Kato T, Fukumoto M (2003) Synthesis and characterization of nanocrystalline iron aluminide intermetallic compounds. Mat Trans 44(12):2678-2687. https://doi.org/10.2320/matertrans.44. 2678

Hussein A, Akbari M, Toghraie D (2018) An experimental study on rheological behavior of a nanofluid containing oxide nanoparticle and proposing a new correlation. Physica E 99:285-293

Ibarrondo I (2008) Review of the strip casting technology by twin roll method, San Sebastian, Spain. ISBN 978-84-612-9489-3

Khaerudini DS, Sardjono MP, Tetuko AP, Sebayang P, Ginting M (2013) Effect of $\mathrm{CeO}_{2}$ addition on the properties of $\mathrm{FeAl}$ based alloy produced by mechanical alloying technique. AIP Conf Proc 1555(7):7-10. https://doi.org/10.1063/1.4820980

Khodadadi H, Toghraie D, Karimipour A (2019) Effects of nanoparticles to present a statistical model for the viscosity of $\mathrm{MgO}$-Water nanofluid powder technology. Powder Technol 342:166-180

Kliestik T, Misankova M, Valaskova K, Svabova L (2018) (2018) Bankruptcy prevention: new effort to reflect on legal and social changes. Sci Eng Ethics 24:791-803. https://doi.org/10.1007/ s11948-017-9912-4

Kliestik T, Nica E, Musa H, Poliak M, Mihai E-A (2020) Networked, smart, and responsive devices in industry 4.0 manufacturing systems. Econ Manag Financ Mark 15(3):23-29. https://doi.org/10. 22381/EMFM15320203

Lenhard R, Malcho M, Jandačka J (2019) Modelling of heat transfer in the evaporator and condenser of the working fluid in the heat pipe. Heat Transf Eng 40(3-4):215-226. https://doi.org/10.1080/ 01457632.2018 .1426225

López-Miranda JL, Rosas R (2019) Hydrogen generation by aluminum hydrolysis using the Fe2A15 intermetallic compound. Int J Hydrogen Energy 41(6):4054-4059. https://doi.org/10.1016/j.ijhydene. 2016.01.012

Mardoyan A, Braun P (2015) Analysis of czech subsidies for solid biofuels. Int J Green Energy 12:405-408. https://doi.org/10.1080/ 15435075.2013.841163

Maroušek J, Myšková K, Žák J (2015) Managing environmental innovation: case study on biorefinery concept. Rev Téc Ing Univ Zulia 38(3):216-220

Maroušek J, Bartoš P, Filip M, Kolăř L, Konvalina P, Maroušková A, Moudrý J, Peterka J, Šál J, Šoch M, Stehel V, Strunecký O, 
Suchý K, Vochozka M, Vrbka J, Zoubek T (2020) Advances in the agrochemical utilization of fermentation residues reduce the cost of purpose-grown phytomass for biogas production. Energy Sources A Recov Util Environ Effects. https://doi.org/10.1080/ 15567036.2020.1738597

Marousek J, Stehel V, Vochozka M, Kolar L, Marouskova A, Strunecký O, Peterka J, Kopecký M, Shreedhar S (2019) Ferrous sludge from water clarification: changes in waste management practices advisable. J Clean Prod 218:459-464

Meyer M, Mendoza-Zélis L, Sánchez FH (1999) Mechanical milling of the intermetallic compound AlFe. Phys Rev B 60(5):3206-3212. https://doi.org/10.1103/PhysRevB.60.3206

Mhadhbi M, Suñol JJ, Khitouni M (2013) Influence of heat treatments on the structure of $\mathrm{FeAl}$ powders mixture obtained by mechanical alloying. Phys Procedia 40:38-44. https://doi.org/10.1016/j. phpro.2012.12.005

Michalcová A, Özkan M, Mikula P, Marek I, Knaislová A, Kopecek J, Vojtech D (2020) The influence of powder milling on properties of SPS compacted FeAl. Molecules 25:2263. https://doi.org/10. 3390/molecules25092263

Moradi A, Toghraie D, Homayoon A, Hosseinian A (2019) An experimental study on MWCNT-water nanofluids flow and heat transfer in double-pipe heat exchanger using porous media. J Therm Anal Calorim 137:1797-1807. https://doi.org/10.1007/ s10973-019-08076-0

Morris DG, Muñoz-Morris MA (2011) Recent developments toward the application of iron aluminides in fossil fuel technologies. Adv Eng Mater 13:43-47. https://doi.org/10.1002/adem.201000210

Paidar V (2015) Iron aluminides and Petr Kratochvíl. Acta Phys Pol A 128:467-469. https://doi.org/10.12693/APhysPolA.128.467

Paul ID, Bhole GP, Chaudhari JR (2014) A Review on green manufacturing: It's important, methodology and its application. Procedia Mater Sci 6:1644-1649. https://doi.org/10.1016/j.mspro.2014. 07.149

Peska M, Karczewski K, Rzeszotarska M, Polanski M (2020) Direct synthesis of $\mathrm{Fe}-\mathrm{Al}$ alloys from elemental powders using laser engineered net shaping. Materials 13:531. https://doi.org/10.3390/ ma13030531

Piatkowski J, Przeliorz R, Jablonska M (2013) The specific heat capacity and oxidation kinetics of $\mathrm{NiAl}, \mathrm{FeAl}$ and $\mathrm{TiAl}$ alloys. Solid State Phenom 203-204:431-434.

Pithawalla YB, Deevi SC, El-Shall MS (2002) Preparation of ultrafine and nanocrystalline FeAl powders. Mater Sci Eng A Struct A329331:92-98. https://doi.org/10.1016/S0921-5093(01)01559-3

Romero-Romero JR, López-Miranda JL, Esparza R, Espinosa-Medina MA, Rosas R (2014) Phase evaluation and its hydrogen correlation of the $\mathrm{FeAl}_{3}$ and $\mathrm{FeAl}_{2}$ intermetallic alloys during mechanical ball-milling with water. Mater Sci Forum 793:143-149

Salazar M, Pérez R, Rosas G (2005) Environmental embrittlement characteristics of the AlFe and AlCuFe intermetallic systems. J New Mater Electrochem Syst 8(2):97-100
Salazar M, López VH, Bautista N, Cuamatzi R, Lagos FA (2016) FeAl powder fabrication by rapid solidification and water vapour-based process. Powder Metall 59(5):314-320. https://doi.org/10.1080/ 00325899.2016 .1228572

Shahsavar A, Khanmohammadi S, Toghraie D, Salihepour H (2019) Experimental investigation and develop ANNs by introducing the suitable architectures and training algorithms supported by sensitivity analysis: measure thermal conductivity and viscosity for liquid paraffin based nanofluid containing $\mathrm{Al}_{2} \mathrm{O}_{3}$ nanoparticles. $\mathrm{J}$ Mol Liq 276:850-860

Sleboda T, Doniec K (2007) The effect of alloy powder morphology on microstructural evolution of hot worked P/M FeAl. Arch Mater Sci Eng 28(10):613-616

Soltani F, Toghraie D, Karimipour A (2020) Experimental measurements of thermal conductivity of engine oil-based hybrid and mono nanofluids with tungsten oxide (WO3) and MWCNTs inclusions. Powder Technol 371:37-44

Soni PR (2001) Mechanical alloying: fundamentals and applications, 1st edn. Cambridge International Science Publishing, Cambridge, pp 6-30

Tecnun, University of Navarra, Spain. www.tecnun.unav.edu

Throne O, Lăzăroiu G (2020) Internet of Things-enabled sustainability, industrial big data analytics, and deep learning-assisted smart process planning in cyber-physical manufacturing systems. Econ Manag Financ Mark 15(4):49-58. https://doi.org/10.22381/ EMFM15420205

Tsakalakis KG, Stamboltzis GA (2004) Modeling the specific grinding energy and ball-mill scale-up IFAC 2004, Nancy, France. Conference: presented at the 11th Symposium on automation in MMM IFAC

Valaskova K, Throne O, Kral P, Michalkova L (2020) Deep learningenabled smart process planning in cyber-physical system based manufacturing. J Self-Gov Manag Econ 8(1):121-127. https://doi. org/10.22381/JSME8120205

Yan SR, Toghraie D, Aziz L, Alizadeh A, Barnoon P, Afrand M (2020) The rheological behavior of MWCNTs-ZnO/water-ethylene glycol hybrid non-Newtonian nanofluid by using of an experimental investigation. J Mater Res Technol 9(8):8401-8406. https://doi. org/10.1016/j.jmrt.2020.05.018

Zamanzade M, Barnoush A, Motz CA (2016) Review on the properties of iron aluminide intermetallics. Curr Comput-Aided Drug Des 6(10):1-29. https://doi.org/10.3390/cryst6010010

Publisher's Note Springer Nature remains neutral with regard to jurisdictional claims in published maps and institutional affiliations. 